\title{
In-patient and residential alternatives to standard acute psychiatric wards in England
}

Sonia Johnson, Helen Gilburt, Brynmor Lloyd-Evans, David P. J. Osborn, Jed Boardman, Morven Leese, Geoff Shepherd, Graham Thornicroft and Mike Slade

\section{Background}

Acute psychiatric wards have been the focus of widespread dissatisfaction. Residential alternatives have attracted much interest, but little research, over the past 50 years.

\section{Aims}

Our aims were to identify all in-patient and residential alternatives to standard acute psychiatric wards in England, to develop a typology of such services and to describe their distribution and clinical populations.

\section{Method}

National cross-sectional survey of alternatives to standard acute in-patient care.

\section{Results}

We found 131 services intended as alternatives. Most were hospital-based and situated in deprived areas, and about half were established after 2000. Several clusters with distinctive characteristics were identified, ranging from general acute wards applying innovative therapeutic models, through clinical crisis houses that are highly integrated with local health systems, to more radical voluntary sector alternatives. Most people using the alternatives had a previous history of admission, but only a few community-based services accepted compulsory admissions.

\section{Conclusions}

Alternatives to standard acute psychiatric wards represent an important, but previously undocumented and unevaluated, sector of the mental health economy. Further evidence is needed to assess whether they can improve the quality of acute in-patient care.

\section{Declaration of interest}

None.
Many service users and professionals are dissatisfied with acute psychiatric hospital care, and it is widely regarded as a problematic component of the UK mental health system. ${ }^{1,2}$ Given the high costs and substantial risks associated with such care, there are also economic and clinical reasons for wishing to ensure it is of the highest possible standard. Thus, a question of considerable interest is whether any residential alternatives to traditional in-patient care can do better, either by delivering care in a different setting, by restricting the diagnostic or demographic range of patients served, or by adopting more coherent and systematic therapeutic models.

The idea that mental health crises might be managed in a setting other than a traditional in-patient ward has a long history. $^{3-7}$ However, we know remarkably little about such alternatives, their availability and distribution, the service models they employ, the clinical populations they serve, and the outcomes they achieve. ${ }^{8}$ A key question is whether, within a modern mental health system, alternatives to traditional in-patient care can achieve good outcomes for patients whose clinical and social difficulties are so severe that in-patient admission would otherwise be required.

This paper presents findings from the first stage of the Alternatives Study, a national investigation of residential alternatives to acute psychiatric in-patient care in England. Our aims were:

(a) to examine the availability of alternatives to standard psychiatric in-patient care in England

(b) to develop a typology of alternatives, describing the characteristics of each main type and the interventions delivered

(c) to describe the demographic and diagnostic profile of the population using the alternatives

(d) to assess equity of access to alternatives, with indicators including their geographical distribution and the extent to which gender and ethnic mix resemble the national in-patient population.

\section{Method}

\section{Inclusion criteria}

A national cross-sectional survey was conducted of alternatives to standard acute psychiatric in-patient care. Ethical approval was obtained from the Metropolitan Multicentre Research Ethics Committee. Services were included if they aimed to serve adults aged 18-65 years who would otherwise be admitted to an acute ward and involved the patient staying overnight at the service. They also had to meet at least one of the following criteria:

- based outside hospital

- dedicated to a specific diagnostic or sociodemographic group

- had a fixed maximum length of stay

- had implemented a specific therapeutic model involving changes in the practice of more than one profession within the service.

Our aim was to prepare the way for further research in this underinvestigated field and to avoid missing any potentially important models by using a broad operationalisation. The risk associated with this strategy is of including services that may not in fact differ greatly from standard wards. However, we judged this risk less important than that of missing important innovative models, especially as Phase 2 of the Alternatives Study involves in-depth investigation of the main models identified, including examination of content of care. Models involving change in only one profession's practice were, however, judged unlikely to be far-reaching enough in their effects on the service's approach for inclusion. We therefore introduced the criterion that practice needed to change for at least two professions. 


\section{Identification of the alternative units}

As no single method was likely to identify all relevant services, multiple methods were used. These included examination of the Mental Health Service Mapping for Adults of Working Age in England, ${ }^{9}$ telephone calls to all mental health trusts, Google internet searches, consultation with a variety of expert sources, including the national voluntary organisations MIND and Rethink, and snowball sampling with identified participants.

\section{Data collection}

All identified services were invited to participate in an interview with a researcher, using a questionnaire designed to cover the main clinical and organisational characteristics of services. Data were collected in the second half of 2005 and first half of 2006. Interviews were usually conducted over the telephone with the manager of the service, who had the opportunity to prepare answers to the questions in advance. Topics covered included location and facilities, types of care provided, referral criteria and pathways, funding and management, links with other services and staffing. So as to characterise the service's client group, participants were also asked for anonymised sociodemographic and clinical details of all residents in their service on the preceding night. To check how comprehensive the identification of alternatives had been, respondents were asked to name any other alternatives of which they were aware in the surrounding area; this yielded only two previously unidentified services.

\section{Ascertainment of deprivation}

Government office region and indices of multiple deprivation ${ }^{10}$ were obtained for the local authority in which each alternative was situated. These indices are estimates of different forms of deprivation derived from multiple data sources, including the 2001 census $^{11}$ and data-sets regarding local benefits, crime, education, housing and health. Six different summary measures make up the overall Index of Multiple Deprivation. Since there is no single best way of comparing area-level deprivation, no single measure is favoured above the others. We therefore explored the distribution of the alternatives according to each summary measure. We also recorded whether each alternative was situated in the centre of one of the ten most populous English cities.

\section{Analysis}

The typology of services was obtained using cluster analysis. This is a statistical technique that allows categorisation of a previously unclassified data-set, based on the principle that cases that resemble each other on a defined set of variables should be grouped together in the same cluster and those that are different on most variables should be in different clusters. ${ }^{12}$ Two-step cluster analysis ${ }^{13}$ was the specific procedure used in this analysis, selected because it allows inclusion of both binary and continuous variables. Variables for the cluster analysis were initially selected from the questionnaire by the Alternatives Study steering group (a group of 19 relevant experts from university, National Health Service (NHS) and voluntary sector backgrounds) who rated each candidate variable for inclusion in the analysis in terms of its importance in characterising the alternatives and discriminating between them. In this way, we identified 18 variables that were rated overall as at least moderately important. The ten that were rated most highly were included in our initial version of the cluster analysis and we then investigated what happened when we added each of the other eight one by one. Our aim in conducting the cluster analysis was to obtain a model that: did not alter very much when small changes were made in the list of variables included; did not have clusters containing a very small or a very large proportion of the sample; and was clinically plausible, in the sense that it grouped the services in a way that could be convincingly interpreted. We tried out models that contained between five and nine clusters to see which fitted best.

\section{Results}

One hundred and thirty-one services meeting the study criteria were identified. The median year in which community-based services had begun to operate was 1999, compared with 2001 for those based in hospitals. The managers of 109 services $(83 \%)$ participated in the study. The 13 variables included in the final model derived from cluster analysis are shown in the Appendix.

A typology containing eight service categories was obtained from the cluster analysis. Table 1 shows their main organisational characteristics. Percentages are shown for ease of interpretation, but small numbers must be borne in mind throughout. Each service type had a clearly distinct set of characteristics.

\section{Community-based service types}

Clinical crisis houses

These were community-based services that bore a greater resemblance than other community alternatives to hospital services. The proportion of the staff who were nurses $(42 \%)$ approached that found in some of the hospital clusters (54-70\%); most had at least one staff member on site awake throughout the night and care programme approach meetings were held in all the services. The care programme approach is a mandatory NHS framework for planning the care of the severely mentally ill. ${ }^{14}$

\section{Specialist crisis houses}

These were community services for specific groups, such as women or people with early psychosis. They resembled the clinical crisis houses on most characteristics.

\section{Crisis team beds}

Services in this group had very small bed numbers, short length of stay and a high level of integration with crisis resolution teams. ${ }^{15}$ Staff teams rarely included nurses and doctors, and this service type had the lowest score for severity of the target group's mental health needs (see Appendix).

\section{Non-clinical alternatives}

Services in this group tended to be managed by the voluntary sector, with limited use of nurses or doctors, though integration with crisis teams was as great as for most hospital ward types. These services were the least likely to have at least one staff member on site awake throughout the night.

\section{Hospital-based service types}

\section{General therapeutic wards}

Services in this cluster were hospital-based and served a range of diagnostic and demographic groups, generally being either local acute admission wards $(n=24)$ or general wards in private hospitals $(n=11)$. Their defining characteristic was a specific therapeutic model. The most frequently reported named acute treatment model was the tidal model, ${ }^{16}$ which focuses on exploring patients' 


\begin{tabular}{|c|c|c|c|c|c|c|c|c|}
\hline & \multicolumn{4}{|c|}{ Hospital-based service types } & \multicolumn{4}{|c|}{ Community-based service types } \\
\hline & $\begin{array}{l}\text { General } \\
\text { therapeutic } \\
\text { wards }\end{array}$ & $\begin{array}{l}\text { Wards for } \\
\text { specific } \\
\text { demographic } \\
\text { groups }^{\mathrm{a}}\end{array}$ & $\begin{array}{l}\text { Therapeutic } \\
\text { wards for } \\
\text { specific } \\
\text { groups }\end{array}$ & $\begin{array}{l}\text { Short-stay wards } \\
\text { and general } \\
\text { wards for } \\
\text { specific groups }\end{array}$ & $\begin{array}{l}\text { Clinical } \\
\text { crisis } \\
\text { houses }\end{array}$ & $\begin{array}{l}\text { Crisis } \\
\text { team } \\
\text { beds }\end{array}$ & $\begin{array}{l}\text { Non- } \\
\text { clinical } \\
\text { alternatives }\end{array}$ & $\begin{array}{l}\text { Specialist } \\
\text { crisis } \\
\text { houses }\end{array}$ \\
\hline Number in group & 35 & 20 & 4 & 8 & 13 & 13 & 11 & 5 \\
\hline Number of beds, mean & 21.1 & 7.2 & 13.0 & 11.0 & 8.8 & 4.5 & 7.0 & 6.4 \\
\hline Typical length of stay, days & 35.8 & 56.4 & 166.7 & 24.1 & 33.0 & 9.5 & 36.0 & 52.2 \\
\hline Single bedrooms for all service users, $n(\%)$ & $23(66)$ & $18(90)$ & $4(100)$ & $4(50)$ & $13(100)$ & $13(100)$ & $11(100)$ & $4(100)$ \\
\hline $\begin{array}{l}\text { Compulsory admissions accepted direct } \\
\text { from community, } n(\%)\end{array}$ & $34(97)$ & $20(100)$ & $4(100)$ & $6(75)$ & $3(23)$ & 0 & 0 & $2(40)$ \\
\hline $\begin{array}{l}\text { Able to accept some compulsorily } \\
\text { detained patients, }{ }^{\mathrm{b}} n(\%)\end{array}$ & $35(100)$ & $20(100)$ & $4(100)$ & $6(75)$ & $11(85)$ & $5(39)$ & $8(73)$ & $4(80)$ \\
\hline Self-referrals accepted, $n(\%)$ & $11(31)$ & $4(20)$ & $1(25)$ & 0 & $3(23)$ & $4(31)$ & $6(55)$ & 0 \\
\hline Maximum length of stay of $\leqslant 7$ days, $n(\%)$ & 0 & 0 & 0 & $2(25)$ & $1(8)$ & $2(15)$ & $4(36)$ & 0 \\
\hline $\begin{array}{l}\text { Care programme approach reviews } \\
\text { organised within the service, } n \text { (\%) }\end{array}$ & $35(100)$ & $20(100)$ & $4(100)$ & $6(75)$ & $13(100)$ & $7(54)$ & $5(45)$ & $5(100)$ \\
\hline $\begin{array}{l}\text { At least one staff member awake and } \\
\text { on site all night, } n(\%)\end{array}$ & $35(100)$ & $20(100)$ & $4(100)$ & $8(100)$ & $11(85)$ & $8(72)$ & $6(55)$ & $5(100)$ \\
\hline $\begin{array}{l}\text { Score for degree of integration with } \\
\text { crisis team }{ }^{c}\end{array}$ & 2.6 & 1.3 & 0.5 & 1.5 & 2.5 & 3.5 & 2.4 & 1.0 \\
\hline Score for severity of target group ${ }^{d}$ & 6.2 & 5.7 & 5.8 & 5.8 & 3.6 & 2.7 & 3.0 & 4.0 \\
\hline $\begin{array}{l}\text { Service users who present a high risk are } \\
\text { referred to appropriate NHS service even if } \\
\text { they do not consent, } n(\%)\end{array}$ & $34(97)$ & $20(100)$ & $4(100)$ & $8(100)$ & $11(92)$ & $13(100)$ & $9(82)$ & $5(100)$ \\
\hline Proportion of staffe ${ }^{\text {who }}$ are nurses, $\%$ & 57 & 54 & 70 & 61 & 42 & 13 & 2 & 43 \\
\hline $\begin{array}{l}\text { Psychiatrist on staff or has specific role } \\
\text { in service, } n(\%)\end{array}$ & $35(100)$ & $20(100)$ & $4(100)$ & $8(100)$ & $6(46)$ & $3(23)$ & $1(9)$ & $5(100)$ \\
\hline $\begin{array}{l}\text { Service users part of the group making } \\
\text { management decisions about operation } \\
\text { of service, } n(\%)\end{array}$ & $19(54)$ & $7(37)$ & $1(25)$ & 7 (78) & $7(54)$ & $6(46)$ & $6(55)$ & $1(20)$ \\
\hline $\begin{array}{l}\text { Managed by voluntary sector organisation, } \\
n(\%)\end{array}$ & 0 & 0 & $2(50)$ & 0 & 0 & 0 & $11(85)$ & $2(5)$ \\
\hline Managed by private company, $n$ (\%) & $11(31)$ & 1 (5) & $1(25)$ & 0 & 0 & 0 & 0 & 0 \\
\hline
\end{tabular}

individual narratives. Other reported models included the Bradford refocusing model, ${ }^{17}$ integration of the ward with the therapeutic programme of a day hospital and, mainly in the case of the private hospitals, provision by ward staff of an extensive programme of group and individual therapy based on cognitive-behavioural principles. Bed numbers were largest for this service type.

Wards for specific demographic groups

All the mother and baby units were placed in one cluster, together with one service for people with hearing impairments. They tended to be fairly small services with a relatively long typical length of stay.

\section{Therapeutic wards for specific groups}

This small group consisted of hospital units with a therapeutic model that targeted a particular diagnostic group such as people with early psychosis or borderline personality disorder. Three of the four were in the voluntary or private sector.
Short-stay wards and general wards for specific groups

A final residual cluster of hospital services comprised wards with a fixed brief length of stay (less than a week in two cases) and others which targeted a particular diagnostic group, such as people with early psychosis, but without implementation of a specific therapeutic model.

\section{Hospital $v$. community services}

The typology produced a complete separation between hospital and community services, with no cluster containing both. Community services were characterised overall by lower severity of target group, fewer medical and nursing staff, and fewer services with on-site staff awake through the night. However, even among the less clinically oriented types of community service, there were indications of considerable collaboration with NHS secondary mental health services. Every service accepted referrals from NHS mental health staff and most named an NHS mental health service as their most prolific referrer. Apart from two clinical crisis houses and two non-clinical alternatives, all 42 community services reported that, in a situation of high risk, they would make a referral to NHS services (e.g. for a Mental Health Act assessment) even for an individual who had not consented to this. 
Only five of the services described as situated in the community reported that they accepted admissions directly from the community of patients compulsorily detained under the Mental Health Act. These services had all acquired the legal status of hospitals, but were described by their managers as not being hospital services: they were typified by having small numbers of beds, not sharing premises with other in-patient services, being unlocked and not being recognisable as in-patient units from outside. Their legal status as hospitals suggests some blurring of boundaries between community and hospital services. The majority of the community-based services included in the survey accepted as transfers from hospital patients who were still legally detained but had been given leave from the hospital.

Table 2 describes the care reported to be available at each service. Not surprisingly, 'medical' interventions such as physical examinations and review of medication were more likely to be available in hospital-based services, but this also applied to most other interventions, including individual psychological treatment, groups, complementary and alternative treatments, and occupational therapy or other organised activity. Again, the clinical and specialist crisis houses were intermediate between the hospital services and the other community services, offering a programme of organised activity in every case, medication review and investigations in the majority, and cognitive-behavioural therapy in around a third of the services.

Table 3 shows the characteristics of the residents in the services on the census night. On the census night, women were in the majority in all models except the clinical crisis houses and specialist crisis houses. Overall, $76 \%$ of the residents of the alternative services were White British, 9\% were Black Caribbean, British or African and 3\% were Other White. Two of the community service types, the non-clinical alternatives and the specialist crisis houses, had especially high representation of ethnic minorities (one non-clinical alternative was a crisis house for people of Black Caribbean or African ethnicity). Except in the non-clinical alternatives, a majority of residents in every service type had a previous history of hospital admission and the clinical and the specialist crisis houses were the types with the highest proportions of residents with current psychotic symptoms (56\% and $72 \%$ respectively). Comparison data from the Count $\mathrm{Me}$ $\mathrm{In}^{18} 2006$ national census of the England and Wales in-patient population are also shown in Table 3.

Table 4 shows the geographical distribution of the alternatives, especially in relation to area social deprivation and region. Most alternatives were situated outside the centres of the ten most populous cities. Nonetheless, far more alternatives were available in local authorities falling in the most deprived quartile than in the least deprived quartile, a finding confirmed by use of several different indices of deprivation, all showing the same pattern (between 52 and $63 \%$ of services were in the most deprived quartile of the country, depending on which index of multiple deprivation was used). At least $70 \%$ of the alternative services were located in the more deprived half of the country. Regional distribution was highly uneven: two-thirds of the alternatives were in London and the South East $(34 \%)$ or in the North East of England (32\%), very few in the South West (3\%), the North West (7\%) and the East of England (6\%).

\section{Discussion}

\section{Limitations}

The major methodological limitation is that data were obtained solely from service managers, with no independent check on accuracy. Social desirability effects are especially likely in response to questions about interventions available, severity of patients' needs and service user involvement. Cluster analysis is rarely definitive - other methods might have led to different classifications; however, the typology that we obtained led to distinct subgroups which were interpretable and remained stable when small changes were made in the variables selected to define the clusters. Finally, a basic assumption was that there is an identifiable group for whom acute in-patient admission is appropriate: in reality, defining this group is difficult and thresholds are likely to vary between clinicians, teams and areas, and to be influenced by acute bed availability.

\begin{tabular}{|c|c|c|c|c|c|c|c|c|}
\hline & \multicolumn{4}{|c|}{ Hospital-based service types } & \multicolumn{4}{|c|}{ Community-based service types } \\
\hline & $\begin{array}{c}\text { General } \\
\text { therapeutic } \\
\text { wards }\end{array}$ & $\begin{array}{l}\text { Wards for } \\
\text { specific } \\
\text { demographic } \\
\text { groups }^{a}\end{array}$ & $\begin{array}{l}\text { Therapeutic } \\
\text { wards for } \\
\text { specific } \\
\text { groups }\end{array}$ & $\begin{array}{l}\text { Short-stay wards } \\
\text { and general } \\
\text { wards for } \\
\text { specific groups }\end{array}$ & $\begin{array}{l}\text { Clinical } \\
\text { crisis } \\
\text { houses }\end{array}$ & $\begin{array}{l}\text { Crisis } \\
\text { team } \\
\text { beds }\end{array}$ & $\begin{array}{c}\text { Non- } \\
\text { clinical } \\
\text { alternatives }\end{array}$ & $\begin{array}{l}\text { Specialist } \\
\text { crisis } \\
\text { houses }\end{array}$ \\
\hline Number in group & 35 & 20 & 4 & 8 & 13 & 13 & 11 & 5 \\
\hline Distinctive therapeutic model, ${ }^{\mathrm{b}} n(\%)$ & $35(100)$ & $3(15)$ & $4(100)$ & $2(25)$ & 0 & 0 & 0 & $5(100)$ \\
\hline $\begin{array}{l}\text { Review of medication by a doctor routinely } \\
\text { provided for everyone, } n(\%)\end{array}$ & $34(97)$ & $20(100)$ & $4(100)$ & $5(63)$ & 9 (59) & $2(15)$ & $4(36)$ & $5(100)$ \\
\hline $\begin{array}{l}\text { Physical examination routine part } \\
\text { of admission procedure, } n(\%)\end{array}$ & $35(100)$ & $20(100)$ & $3(75)$ & $8(100)$ & $7(54)$ & 0 & 0 & $2(40)$ \\
\hline $\begin{array}{l}\text { Blood test can be carried out at service, } \\
n(\%)\end{array}$ & $34(97)$ & $20(100)$ & $4(100)$ & $8(100)$ & $7(54)$ & $2(15)$ & $1(9)$ & $4(80)$ \\
\hline $\begin{array}{l}\text { Recognised type of individual } \\
\text { psychological treatment available, } n(\%)\end{array}$ & $22(63)$ & $13(65)$ & $4(100)$ & $4(50)$ & $4(31)$ & $3(23)$ & $2(18)$ & $3(60)$ \\
\hline $\begin{array}{l}\text { Cognitive-behavioural therapy available, } \\
n(\%)\end{array}$ & $20(57)$ & $13(65)$ & $3(75)$ & $4(50)$ & $4(31)$ & $3(23)$ & $1(9)$ & $2(40)$ \\
\hline $\begin{array}{l}\text { Complementary or alternative therapies } \\
\text { available, } n(\%)\end{array}$ & $14(41)$ & $9(45)$ & $1(25)$ & $3(38)$ & $4(31)$ & $3(23)$ & $2(18)$ & $3(60)$ \\
\hline $\begin{array}{l}\text { Programme of occupational therapy or } \\
\text { other organised activities available, } n \text { (\%) }\end{array}$ & $35(100)$ & $19(95)$ & $4(100)$ & $3(38)$ & $13(100)$ & $2(15)$ & $4(36)$ & $5(100)$ \\
\hline Group programme held at service, $n(\%)$ & $34(97)$ & $17(85)$ & $3(75)$ & $6(75)$ & $8(77)$ & $3(17)$ & $5(45)$ & $4(80)$ \\
\hline
\end{tabular}


Table 3 Characteristics of patients in residence at 1-night census

\begin{tabular}{|c|c|c|c|c|c|c|c|c|}
\hline & $\begin{array}{l}\text { Male } \\
\text { residents } \\
n / N(\%)\end{array}$ & $\begin{array}{l}\text { White } \\
\text { British } \\
n(\%)^{\text {a }}\end{array}$ & $\begin{array}{c}\text { Black } \\
\text { Caribbean, } \\
\text { British or } \\
\text { African } n(\%)\end{array}$ & $\begin{array}{c}\text { Other } \\
\text { White } \\
n(\%)\end{array}$ & $\begin{array}{l}\text { Asian } \\
n(\%)\end{array}$ & $\begin{array}{l}\text { History of } \\
\text { previous } \\
\text { admission }^{\text {b }} \\
n(\%)\end{array}$ & $\begin{array}{l}\text { Com- } \\
\text { pulsorily } \\
\text { detained }^{\mathrm{c}} \\
n(\%)\end{array}$ & $\begin{array}{c}\text { Psychotic } \\
\text { symptoms }^{d} \\
n(\%)\end{array}$ \\
\hline \multicolumn{9}{|l|}{ Hospital-based services } \\
\hline General therapeutic wards & 259/571 (45) & $445(78)$ & $26(10)$ & $18(3)$ & $22(4)$ & $395(70)$ & $207(36)$ & $285(50)$ \\
\hline Therapeutic wards for specific groups & $10 / 44(23)$ & $30(68)$ & $10(23)$ & $2(5)$ & $1(2)$ & $24(54)$ & $25(57)$ & $20(45)$ \\
\hline Wards for specific demographic groups ${ }^{e}$ & $4 / 92(4)$ & $65(71)$ & $10(11)$ & $1(1)$ & $10(11)$ & $59(64)$ & $14(15)$ & $38(41)$ \\
\hline $\begin{array}{l}\text { Short-stay wards and general wards } \\
\text { for specific groups }\end{array}$ & $37 / 84(44)$ & $71(85)$ & $5(6)$ & 0 & $2(2)$ & $68(81)$ & $33(39)$ & $44(52)$ \\
\hline \multicolumn{9}{|l|}{ Community-based services } \\
\hline Clinical crisis houses & 48/93 (51) & $80(86)$ & $6(6)$ & $3(3)$ & $3(3)$ & $80(86)$ & $9(10)$ & $52(56)$ \\
\hline Crisis team beds & $13 / 48(27)$ & $38(79)$ & $7(15)$ & $1(2)$ & $1(2)$ & $33(69)$ & $0(0)$ & $14(29)$ \\
\hline Non-clinical alternatives & $21 / 61(34)$ & $37(61)$ & $14(23)$ & $2(3)$ & $4(7)$ & $24(39)$ & $1(2)$ & $13(21)$ \\
\hline Specialist crisis houses & $17 / 29(59)$ & $10(34)$ & $9(3)$ & $2(7)$ & $5(17)$ & $24(83)$ & $11(38)$ & $21(72)$ \\
\hline Total & 409/1022 (40) & $776(76)$ & $87(9)$ & $29(3)$ & $48(5)$ & $648(63)$ & $300(29)$ & $487(48)$ \\
\hline National in-patient population ${ }^{f}$ & $55.3 \%$ & $79.5 \%$ & $7.8 \%$ & $5.6 \%$ & $3.2 \%$ & - & $40 \%$ & - \\
\hline \multicolumn{9}{|c|}{$\begin{array}{l}\text { a. This table describes ethnic group, as recorded in clinical records, for } 940 \text { of the resident clients. Thirty-three further residents were categorised as of 'other' or 'mixed' ethnic } \\
\text { group, and a clear categorisation of ethnic group was unavailable for the remaining forty-nine. Data are complete regarding gender and whether compulsorily detained under the } \\
\text { Mental Health Act. } \\
\text { b. This column reports all residents for whom the manager was aware of a history of admission as a proportion of the total. } \\
\text { c. All patients currently subject to compulsory hospitalisation under the Mental Health Act included here, including those officially on leave from the hospital. } \\
\text { d. All residents for whom the manager was aware of psychotic symptoms during the current admission as a proportion of the total. } \\
\text { e. Mother and baby units. } \\
\text { f. Count Me In } 20066^{18} \text { These are data for mental health patients (excluding intellectual disability) from the } 2006 \text { Count Me In census, carried out shortly after our survey. So that } \\
\text { categories correspond as closely as possible with our survey, Black Caribbean, Black African and Other Black are grouped together, as are White Other and White Irish, and Indian, } \\
\text { Pakistani, Bangladeshi, Other Asian and Chinese. }\end{array}$} \\
\hline
\end{tabular}

Table 4 Geographical distribution of the alternatives

\begin{tabular}{|c|c|c|c|c|c|c|c|c|c|}
\hline & \multicolumn{5}{|c|}{ Hospital-based service types } & \multicolumn{4}{|c|}{ Community-based service types } \\
\hline & Total & $\begin{array}{c}\text { General } \\
\text { therapeutic } \\
\text { wards }\end{array}$ & $\begin{array}{l}\text { Wards for } \\
\text { specific } \\
\text { demographic } \\
\text { groups }^{\mathrm{a}}\end{array}$ & $\begin{array}{l}\text { Therapeutic } \\
\text { wards for } \\
\text { specific } \\
\text { groups }\end{array}$ & $\begin{array}{l}\text { Short-stay } \\
\text { wards and } \\
\text { general wards } \\
\text { for specific } \\
\text { groups }\end{array}$ & $\begin{array}{l}\text { Clinical } \\
\text { crisis } \\
\text { houses }\end{array}$ & $\begin{array}{l}\text { Crisis } \\
\text { team } \\
\text { beds }\end{array}$ & $\begin{array}{c}\text { Non- } \\
\text { clinical } \\
\text { alternatives }\end{array}$ & $\begin{array}{c}\text { Specialist } \\
\text { crisis } \\
\text { houses }\end{array}$ \\
\hline \multicolumn{10}{|l|}{ Government office region, $n$ (\%) } \\
\hline North West & $8(7)$ & 0 & $2(10)$ & 0 & $3(38)$ & $2(15)$ & 0 & $1(9)$ & 0 \\
\hline North East and Yorkshire & $35(32)$ & $17(49)$ & $4(20)$ & $2(5)$ & $2(25)$ & $5(39)$ & $3(23)$ & $1(9)$ & $1(20)$ \\
\hline South West & (3) & 0 & $3(15)$ & 0 & 0 & 0 & 0 & 0 & 0 \\
\hline South East and London & 37 (34) & $11(31)$ & $6(30)$ & $2(5)$ & $2(25)$ & $2(15)$ & $7(54)$ & $6(55)$ & $1(20)$ \\
\hline Midlands (East and West) & $19(17)$ & $6(17)$ & $3(15)$ & 0 & 0 & $3(23)$ & $2(15)$ & $2(18)$ & $3(60)$ \\
\hline East & $7(6)$ & $1(3)$ & $2(10)$ & 0 & $1(13)$ & $1(8)$ & $1(8)$ & $1(9)$ & 0 \\
\hline In the inner city, $n(\%)$ & $34(31)$ & $12(34)$ & $7(35)$ & $2(50)$ & $2(25)$ & $1(8)$ & $2(15)$ & $4(36)$ & $4(80)$ \\
\hline \multicolumn{10}{|c|}{$\begin{array}{l}\text { Index of Multiple Deprivation, }{ }^{\mathrm{C}} \mathrm{n}(\%) \\
\text { Average rank of local authority scores (overall score) }\end{array}$} \\
\hline Services based in most deprived quartile & $57(52)$ & $17(49)$ & $7(35)$ & $2(50)$ & $5(63)$ & $7(54)$ & $6(46)$ & $8(73)$ & $5(100)$ \\
\hline Services based in most deprived half & 77 (71) & $26(74)$ & $10(50)$ & $2(50)$ & $7(88)$ & $9(69)$ & 10 & $8(73)$ & $5(100)$ \\
\hline \multicolumn{10}{|l|}{ Rank of income scale } \\
\hline Services based in most deprived quartile & $68(62)$ & $21(60)$ & $9(45)$ & $2(50)$ & $7(88)$ & $9(69)$ & $7(54)$ & $8(73)$ & $5(100)$ \\
\hline Services based in most deprived half & $88(81)$ & $29(83)$ & $15(75)$ & $4(100)$ & $7(88)$ & $13(100)$ & $9(69)$ & $8(73)$ & $5(100)$ \\
\hline \multicolumn{10}{|l|}{ Rank of employment scale } \\
\hline Services based in most deprived quartile & $69(63)$ & $22(63)$ & $11(55)$ & $2(50)$ & $6(75)$ & $9(69)$ & $7(54)$ & $7(64)$ & $5(100)$ \\
\hline Services based in most deprived half & $89(82)$ & $28(80)$ & $15(75)$ & $4(100)$ & $7(88)$ & $12(92)$ & $9(69)$ & $9(82)$ & $5(100)$ \\
\hline $\begin{array}{l}\text { a. All but one in this group were mother and baby } \\
\text { b. Ten most populous cities. } \\
\text { c. For simplicity, only three of the six indices of } m \\
\text { shown (further details available from S.J.). The figu } \\
\text { deprived half. }\end{array}$ & its. & are st & his table, & remainin & $\begin{array}{l}\text { e were also } \\
\text { ed quartile }\end{array}$ & ated & $\begin{array}{l}\text { owed } \\
\text { and t }\end{array}$ & $\begin{array}{l}\text { similar } \\
\text { ortion i }\end{array}$ & $\begin{array}{l}\text { in to those } \\
\text { most }\end{array}$ \\
\hline
\end{tabular}

\section{Availability of alternatives}

Our findings indicate substantial previously unreported activity in the development of alternatives to standard in-patient care. Assuming similar numbers of beds for non-responders to our survey as for responders, we estimate that there are just under 1300 occupied beds in these alternative units, of which around 250 are outside hospital and 380 in the private sector. This compares with a national tally of around 12400 acute beds for adults of working age. ${ }^{19}$ Thus, these alternatives now represent an important, but so far largely undocumented, uncoordinated and unevaluated component of the national mental health economy, mainly within the statutory sector.

\section{Types of alternative}

A spectrum of alternatives was identified. In hospital settings, the most popular form of initiative has been the introduction of 
distinctive therapeutic models such as the tidal model ${ }^{16}$ on general acute wards. An advantage of such a strategy is that no substantial reorganisation of the local mental health system is required, but a literature search found no evidence from randomised controlled trials or any other large-scale evaluations regarding any of these named models of in-patient care. Some of their components, for example giving priority to the service user's narrative and increasing staff-patient contact, sound like goals that one might expect any mainstream service aiming for high standards to adopt rather than distinctive approaches. Data at this stage of the study allow us only to identify approaches that aim to be innovative, not to establish whether the resulting care and environment are really different from standard services in important respects. Our study criteria classify the adoption of distinctive therapeutic models on general acute wards as an alternative to standard care. However, they might also be viewed as approaches intended to improve quality within the framework of standard care, arguably a goal that may yield more widespread benefits than development of alternatives. $^{20}$

Brief-admission wards are one of the few forms of alternative to have any supporting evidence, though all the studies identified in a systematic review dated from before $1985 .{ }^{21}$ These early studies suggested that short hospital stays were as effective as standard ones, but little research or service development has followed on from them. Detailed evaluation of the two hospital units we found that reported a maximum length of stay of less than a week would thus be of considerable interest. The international literature also yields descriptions of services specialising in particular subgroups, based on demographic characteristics such as ethnic group ${ }^{22}$ or on diagnosis. ${ }^{23}$ This has some potential to allow development of more focused therapeutic models for in-patient care, but mother and baby units are currently the only type of specialist acute unit found on any scale within the NHS.

In the community, new service types with distinctive sets of characteristics are emerging around England. They range from community-based services that retain a substantial resemblance to hospital wards, through short-stay community beds very closely linked to, and sometimes directly managed by, crisis resolution teams, to more radical community alternatives. The close links between most community alternatives and (other) NHS secondary mental health services suggest that they function as components in local acute care systems and pathways rather than freestanding services that attract different client groups. However, we cannot assess from our data whether patients are in practice offered a choice between hospital admission and these community alternatives. Notable by its absence from current service provision in England was one model with a long history on both sides of the Atlantic: the family sponsor home $e^{24,25}$ in which acutely unwell patients are placed with carefully trained and selected families, supported by a home treatment team.

\section{Types of care}

Some types of care reported to be available within the hospital services were less likely to be provided in community alternatives. Examples were psychological treatments, structured activity programmes, physical investigations and review of medication. We do not know how far the use of resources outside the units compensated for some of these apparent gaps (e.g. crisis resolution teams may be major providers of interventions such as medication review and supervision in some alternatives). Some of the ways in which alternatives may help their clients, such as through service user empowerment and peer support, may not have been well captured by our survey. If alternatives encourage service users to become involved in mainstream activities in the community, this may serve social inclusion better than organised activities in mental health service settings. However, medication review, physical health assessment and psychological treatments are important components of the management of disorders such as bipolar affective disorder and schizophrenia. ${ }^{26,27}$ Service planners thus need to guard against developing community alternatives in which there is less access to some important treatments for severe mental illness than in hospital settings. Lack of activity and of clear therapeutic models are among the recurrent criticisms of in-patient services, ${ }^{28,29}$ and alternatives that do not offer organised activities, psychological treatments or a defined therapeutic model may not be addressing these problems. However, some community alternatives do provide a wide range of types of medical, psychological and social care, suggesting that this is feasible in a community setting given adequate resources.

\section{Clinical populations served}

The large proportions of service users who have current psychotic symptoms and/or a previous history of admission suggest that the alternatives are focusing on a group with severe mental illness. We cannot, however, say whether their severity of risk and disturbance at the time of admission was as great as in hospital services. The less clinically focused community alternatives - crisis beds and non-clinical alternatives - reported fewer residents with psychotic symptoms. This may well be appropriate: people with acute psychoses are likely to need a range of clinical interventions delivered by mental health professionals, as is offered in hospitals and the more clinical community alternatives, whereas people with other types of mental health problem (e.g. depression or personality disorder) may benefit from a markedly different approach. However, further evidence is needed as to whether the groups served by these non-clinical alternatives overlap with acute-ward patients or whether they are new groups who would not otherwise receive a residential acute service.

A significant limitation of many community services is that they manage mainly voluntary rather than compulsorily detained patients. Thus, any increase in choice about care will be available only to those in-patients who are, in any case, less subject to compulsion (though it is possible that some people admitted voluntarily to community alternatives would otherwise be detained in hospital). The fact that some community alternatives do accept detained patients, albeit in very small numbers, is of considerable interest, suggesting scope for further development of alternatives to meet the needs of such patients.

\section{Equity of access}

Men are in a slight majority among in-patients nationally, ${ }^{18}$ but the reverse applies to alternative services. Intensive home treatment has also been found to prevent more female than male admissions $^{30}$ so that overall, women may have more access to alternatives to standard acute admission. This may reflect differences in actual or perceived severity or risks, or in willingness to engage: the imbalance warrants further investigation as equity of access to a range of types of acute care is desirable if feasible.

Availability of alternatives is especially salient for people from those minority ethnic groups, who are overrepresented in in-patient settings and for whom coercive pathways to care are especially likely. ${ }^{31}$ The proportion of White British residents and that of Black Caribbean, Black African and Black British residents were very similar to the national in-patient population; other groups also diverged relatively little from the national picture. Caution needs to be exercised in interpreting this, as adjustment is not made for the local ethnic mix, but it provides a preliminary 
indication that the full range of groups represented in hospital is also served by alternative services.

The uneven distribution between regions is potentially inequitable and probably reflects the origins of alternative services in local interest rather than central policy and planning. A more encouraging finding is their tendency to develop in deprived areas, suggesting that they may be a response to high levels of local need. ${ }^{32}$ Given this, it is surprising that relatively few have developed within inner-city areas.

\section{Further research}

Given the pressing need to improve acute care, the substantial investment of public funds in these alternatives and the fact that some are relatively long established, they have been remarkably underinvestigated. Prior to the present survey, a few descriptions and, occasionally, evaluations ${ }^{33,34}$ have appeared of model services, but these are the exception. Evaluative research is thus urgently needed to explore their effectiveness, which alternatives work best for which groups of service users, and whether, as intended, they resolve some of the problems in acute care systems. Such research is required both to assess whether provision of these alternatives is an effective use of public funds, and, if some alternatives are indeed an improvement on standard care, to secure their futures and allow dissemination of effective ways of working.

\section{Appendix}

\section{Variables used to obtain typology of services}

1. Number of beds

2. Voluntary sector management

3. Typical length of stay, reported by manager

4. Proportion of staff who are nurses

5. Whether outside hospital

6. Whether care programme approach meetings (care planning meetings which are a statutory requirement within the NHS) are organised within the service

7. Whether any programme of structured activity is available to residents 8. Whether service is dedicated to people with a specific diagnosis

9. Whether service is dedicated to a specific sociodemographic group

10. Implementation of a specific therapeutic model

11. Score for degree of integration with crisis resolution team, measured by a scale made up from six binary items (maximum score 6, Cronbach's $\alpha$ for scale 0.69):

- whether crisis resolution teams can refer to the service

- whether a crisis resolution team is among the top three referrers

- whether crisis resolution teams are the only referrers

- whether a crisis resolution team decides who can be admitted to the service ('gate-keeping')

- whether a crisis resolution team manages the service

- whether the service's premises are shared with a crisis resolution team

12. Score for extent of hospital-like interventions, measured by scale with six binary items (maximum score $6 ; \alpha=0.91$ ):

- whether staff hold and dispense all medications

- whether blood tests can be carried out on site

- whether physical examination is part of standard admission procedures
- whether one-to-one supervision can be carried out for at least $12 \mathrm{~h}$

- whether residents on medication are normally reviewed by a doctor during their stay

- whether the staff team includes a doctor

13. Score for severity of target group, measured by scale including seven binary items (maximum score $7 ; \alpha=0.73$ ):

- whether all admissions are for an acute crisis otherwise requiring standard acute ward admission

- whether such admissions are the top priority

- whether admissions are on day of referral when beds are available

- whether compulsorily detained patients are accepted directly from community

- whether detained patients are admitted on any basis, including on leave from hospital

- whether manager judges at least $50 \%$ of residents similar in severity to general acute ward patients

- whether history of violence is an exclusion criterion.

Sonia Johnson, MRCPsych, DM, Department of Mental Health Sciences, University College London; Helen Gilburt, BSc, PhD, Health Services and Population Research Department, Institute of Psychiatry, King's College London; Brynmor Lloyd-Evans, BA, MSC, David P. J. Osborn, MRCPsych, PhD, Department of Mental Health Sciences, University College London; Jed Boardman, FRCPsych, PhD, Morven Leese, PhD, Health Services and Population Research Department, Institute of Psychiatry, King's College London; Geoff Shepherd, MPhil, PhD, Sainsbury Centre for Mental Health, London; Graham Thornicroft, FRCPsych, PhD, Mike Slade, DPsych, PhD, Health Services and Population Research Department, Institute of Psychiatry, King's College London, UK

Correspondence: Sonia Johnson, Department of Mental Health Sciences, University College London, 2nd Floor, Charles Bell House, 67-73 Riding House Street, London W1W 7EJ. Email: s.johnson@ucl.ac.uk

First received 24 Feb 2008, final revision 24 Sep 2008, accepted 29 Oct 2008

\section{Acknowledgements}

We are very grateful to the managers of the participating services who gave their time generously and also for the very helpful input of the members of the Alternatives Study steering group. This report presents independent research commissioned by the National Institute for Health Research (NIHR) Service Delivery and Organisation Programme. The views expressed in this publication are those of the authors and not necessarily those of the National Health Service, the NIHR or the Department of Health.

\section{References}

1 Quirk A, Lelliott P. What do we know about life on acute psychiatric wards in the UK? A review of the research evidence. Soc Sci Med 2001; 53: 1565-74.

2 Rose D. Users' Voices. The Perspectives of Mental Health Service Users on Community and Hospital Care. The Sainsbury Centre, 2001.

3 Allderidge P. Hospitals, madhouses and asylums: cycles in the care of the insane. Br J Psychiatry 1979; 134: 321-34.

4 Stroul BA. Residential crisis services: a review. Hosp Community Psychiatry 1988; 39: 1095-9.

5 Warner R. Introduction. In Alternatives to the Hospital for Acute Psychiatric Treatment (ed R Warner). American Psychiatric Press, 1995

6 Bola JR, Mosher LR. Treatment of acute psychosis without neuroleptics. Twoyear outcomes from the Soteria project. J Nerv Ment Dis 2003; 191: 219-29.

7 Goldstein JL, Godemont MML. The legend and lessons of Geel, Belgium: a 1500-year-old legend, a 21st century model. Community Ment Health J 2003; 39: 441-58.

8 Lloyd-Evans B, Slade M, Jagielska D, Johnson S. Residential alternatives to acute psychiatric hospital admission: systematic review. Br J Psychiatry 2009; in press.

9 Glover G, Bennett K, Bradley S, Barnes D. Mental Health Service Mapping for Working Age Adults. Centre for Public Mental Health, University of Durham, 2006 (http://www.dur.ac.uk/service.mapping/amh).

10 Jordan $\mathrm{H}$, Roderick $\mathrm{P}$, Martin D. The Index of Multiple Deprivation 2000 and accessibility effects on health. J Epidemiol Community Health 2004; 58: 250-7. 
11 Office for National Statistics. Census 2001. ONS, 2001 (http:// www.statistics.gov.uk/census2001).

12 Everitt B. Commentary: classification and cluster analysis. BMJ 1995; 311: 535-6.

13 SPSS. The SPSS Two Step Cluster Component. SPSS, 2001 (ftp:// ftp.spss.com/pub/web/wp/TSCWP-0101.pdf).

14 The Care Programme Approach Association. About the Care Programme Approach (CPA). CPAA, 2008 (http://www.cpaa.org.uk/ thecareprogrammeapproach).

15 Lloyd-Evans B, Johnson S, Gilburt H. Integration between crisis resolution teams and residential crisis teams. In Crisis Resolution and Home Treatment in Mental Health (eds S Johnson, J Needle, J Bindman, G Thornicroft). Cambridge University Press, 2008.

16 Fletcher $\mathrm{E}$, Stevenson $\mathrm{C}$. Launching the Tidal Model in an adult mental health programme. Nurs Stand 2001; 15: 33-6.

17 Bowles N. Mental health in-patient settings. In New Approaches to Preventing Suicide (eds D Duffy, T Ryan). Jessica Kingsley Publishers, 2004.

18 Healthcare Commission. Count Me In. Results of a National Census of Inpatients in Mental Health Hospitals and Facilities in England and Wales. Commission for Healthcare Audit and Inspection, 2006 (http:// www.healthcarecommission.org.uk/_db/_documents/Count_Me_In_2006.pdf).

19 Department of Health. Hospital activity statistics. Department of Health, 2006 (http://www.performance.doh.gov.uk/hospitalactivity/)

20 Royal College of Psychiatrists. Accreditation for Acute Inpatient Mental Health Services (AIMS). Royal College of Psychiatrists, 2008 (http:// www.rcpsych.ac.uk/researchandtrainingunit/centreforqualityimprovement/ aims.aspx).

21 Johnstone $P$, Zolese $G$. Systematic review of the effectiveness of planned short hospital stays for mental health care. BMJ 1999; 318: 1387-90.

22 Mathews CA, Glidden D, Murray S, Forster P, Hargreaves WA. The effect on treatment outcomes of assigning patients to ethnically focused inpatient psychiatric units. Psychiatr Serv 2002; 53: 830-5.
23 Bonsack C, Borgeat F, Dubois A. Impact of mental health services' specialization by diagnosis in Lausanne: I. Qualitative study. Ann Med Psychol (Paris) 2001; 159: 645-51.

24 Johnson S, Gilburt H, Lloyd-Evans B, Slade M. Acute in-patient psychiatry: residential alternatives to hospital admission. Psychiatr Bull 2007; 31: 262-4.

25 Polak P, Kirby M, Deitchman W. Treating acutely psychotic patients in private homes. New Dir Ment Health Serv 1979; 1: 49-64.

26 National Institute for Health and Clinical Excellence. Schizophrenia. Core Interventions in the Treatment and Management of Schizophrenia in Primary and Secondary Care. NICE, 2002.

27 National Institute for Health and Clinical Excellence. Bipolar Disorder. The Management of Bipolar Disorder in Adults, Children and Adolescents, in Primary and Secondary Care. NICE, 2006.

28 Szmukler G, Holloway F. In-patient treatment. In Textbook of Community Psychiatry (eds G Thornicroft, G Szmukler): 321-37. Oxford University Press, 2001.

29 Sainsbury Centre for Mental Health. Acute Problems. A Survey of the Quality of Care in Acute Psychiatric Units. Sainsbury Centre for Mental Health, 1998.

30 Glover G, Arts G, Babu KS. Crisis resolution/home treatment teams and psychiatric admission rates in England. Br J Psychiatry 2006; 189: 441-5.

31 Bhui K, Stansfeld S, Hull S, Priebe S, Mole F, Feder G. Ethnic variations in pathways to and use of specialist mental health services in the UK. Systematic review. Br J Psychiatry 2003; 182: 105-16.

32 Harrison J, Barrow S, Creed F. Social deprivation and psychiatric admission rates among different diagnostic groups. Br J Psychiatry 1995; 167: 456-62.

33 Boardman AP, Hodgson RE, Lewis M, Allen K. North Staffordshire Community Beds Study: Iongitudinal evaluation of psychiatric in-patient units attached to community mental health centres. I: Methods, outcome and patient satisfaction. Br J Psychiatry 1999: 175: 70-8.

34 Fenton WS, Mosher LR, Herrell JM, Blyler CR. Randomized trial of general hospital and residential alternative care for patients with severe and persistent mental illness. Am J Psychiatry 1998; 155: 516-22.

\section{Melancholia}

\section{Max Fink and Michael A. Taylor}

Melancholia is a classical episodic depressive disorder that combines mood, psychomotor, cognitive and vegetative components with high suicide risk. In the present psychiatric classification it is buried as a modifier in both bipolar and unipolar depressions. It is hardly used to characterise patients in the clinic or research. The syndrome is frequently recognised in delusional and agitated depression, and in the elderly. Cortisol or sleep EEG abnormalities are prognostically helpful. Melancholia is particularly responsive to tricyclic antidepressants and electroconvulsive therapy but not to selective serotonin reuptake inhibitors or psychotherapy. Recognising melancholia as a distinct disorder improves clinical care and research. 